Argonne

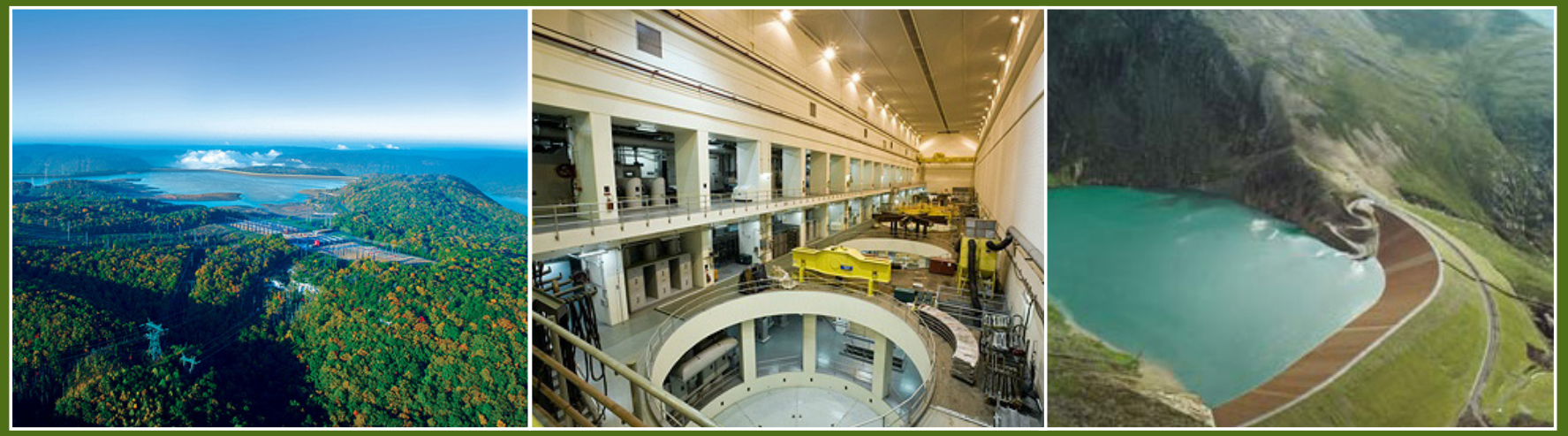

\title{
Modeling Ternary Pumped Storage Units
}

Decision and Information Sciences 


\begin{abstract}
About Argonne National Laboratory
Argonne is a U.S. Department of Energy laboratory managed by UChicago Argonne, LLC under contract DE-AC02-06CH11357. The Laboratory's main facility is outside Chicago, at 9700 South Cass Avenue, Argonne, Illinois 60439. For information about Argonne and its pioneering science and technology programs, see www.anl.gov.
\end{abstract}

\title{
Availability of This Report
}

This report is available, at no cost, at http://www.osti.gov/bridge. It is also available on paper to the U.S. Department of Energy and its contractors, for a processing fee, from:

U.S. Department of Energy

Office of Scientific and Technical Information

P.O. Box 62

Oak Ridge, TN 37831-0062

phone (865) 576-8401

fax (865) 576-5728

reports@adonis.osti.gov

\section{Disclaimer}

This report was prepared as an account of work sponsored by an agency of the United States Government. Neither the United States Government nor any agency thereof, nor UChicago Argonne, LLC, nor any of their employees or officers, makes any warranty, express or implied, or assumes any legal liability or responsibility for the accuracy, completeness, or usefulness of any information, apparatus, product, or process disclosed, or represents that its use would not infringe privately owned rights. Reference herein to any specific commercial product, process, or service by trade name, trademark, manufacturer, or otherwise, does not necessarily constitute or imply its endorsement, recommendation, or favoring by the United States Government or any agency thereof. The views and opinions of document authors expressed herein do not necessarily state or reflect those of the United States Government or any agency thereof, Argonne National Laboratory, or UChicago Argonne, LLC.

This report is being disseminated by the Department of Energy. As such, this document was prepared in compliance with Section 515 of the Treasury and General Government Appropriations Act for Fiscal Year 2001 (Public Law 106-554) and Information Quality Guidelines issued by the Department of Energy. Although this report does not constitute "influential" information, as that term is defined in DOE's Information Quality Guidelines or the Office of Management and Budget's Information Quality Bulletin for Peer Review, the study was reviewed both internally and externally prior to publication. For purposes of external review, the study benefited from the advice and comments of an advisory working group consisting of more than 30 experts from the industry, government, and research institutions. 


\section{Modeling Ternary Pumped Storage Units}

prepared for

U.S. Department of Energy - Wind and Water Power Technologies Office

prepared by

Vladimir Koritarov and Leah Guzowski

Decision and Information Sciences, Argonne National Laboratory

James Feltes, Yuriy Kazachkov and Bo Gong

Siemens PTI

Bruno Trouille and Peter Donalek

MWH Americas

Vahan Gevorgian

National Renewable Energy Laboratory

August 2013 
This page intentionally left blank. 


\section{Preface}

This report is one of several reports developed during the U.S. Department of Energy (DOE) study on the Modeling and Analysis of Value of Advanced Pumped Storage Hydropower in the United States. The study is led by Argonne National Laboratory in collaboration with Siemens PTI, Energy Exemplar, MWH Americas, and the National Renewable Energy Laboratory. Funding for the study was provided by DOE's Office of Energy Efficiency and Renewable Energy (EERE) through a program managed by the EERE's Wind and Water Power Technologies Office (WWPTO).

The scope of work for the study has two main components: (1) development of vendorneutral dynamic simulation models for advanced pumped storage hydro (PSH) technologies and (2) production cost and revenue analyses to assess the value of PSH in the power system. Throughout the study, the project team was supported and guided by an Advisory Working Group (AWG) consisting of more than 30 experts from a diverse group of organizations including the hydropower industry and equipment manufacturers, electric power utilities and regional electricity market operators, hydro engineering and consulting companies, national laboratories, universities and research institutions, hydropower industry associations, and government and regulatory agencies.

The development of vendor-neutral models was carried out by the Advanced Technology Modeling Task Force Group (TFG) led by experts from Siemens PTI, with the participation of experts from other project team members. First, the Advanced Technology Modeling TFG reviewed and prepared a summary of the existing dynamic models of hydro and PSH plants that are currently in use in the United States. This is published in the report Review of Existing Hydroelectric Turbine-Governor Simulation Models. The review served to determine the needs for improving existing models and developing new ones.

While it was found that the existing dynamic models for conventional hydro and PSH plants allow for the accurate representation and modeling of these technologies, it was concluded that there is a need to develop dynamic models for two PSH technologies for which, at present, there were no existing models available in the United States. Those two technologies are (1) adjustable speed PSH plants employing doubly-fed induction machines (DFIMs), and (2) ternary PSH units. The Advanced Technology Modeling TFG developed vendor-neutral models of these two PSH technologies, and they are published in two reports: (1) Modeling Adjustable Speed Pumped Storage Hydro Units Employing Doubly-Fed Induction Machines and (2) Modeling Ternary Pumped Storage Units.

Extensive testing of newly developed models was performed using the Siemens PTI's standard test cases for the Power System Simulator for Engineering (PSS ${ }^{\circledR} E$ ) model as well as the Western Electricity Coordinating Council's (WECC's) modeling cases for Western Interconnection that were provided in PSS $\triangle E$ format. The results of model 
testing are presented in the report Testing Dynamic Simulation Models for Different Types of Advanced Pumped Storage Hydro Units.

In addition to the project team members and DOE, all these reports have been reviewed by the AWG members, and their comments and suggestions have been incorporated into the final versions of the reports. Parts of these reports will also be included in the final report for the entire study to illustrate the model development component of the work. 


\section{Acknowledgments}

The authors would like to acknowledge the support and guidance provided to the project team by the staff and contractors of the DOE/EERE's Wind and Water Power Technologies Office (WWPTO), including Michael Reed, Rajesh Dham, Charlton Clark, Rob Hovsapian, Patrick O'Connor, Richard Gilker, and others. The authors are also grateful to the members of the Advisory Working Group for their excellent collaboration and efforts in advising the project team and guiding the study. The Advisory Working Group included a broad spectrum of global pumped storage hydropower specialists including:

\begin{tabular}{|c|c|}
\hline $\begin{array}{l}\text { Rajesh Dham, Charlton Clark, Rob } \\
\text { Hovsapian, Patrick O'Connor, Richard Gilker }\end{array}$ & $\begin{array}{l}\text { DOE/EERE - Wind and Water Power Technologies } \\
\text { Office (EERE) }\end{array}$ \\
\hline Rachna Handa & $\begin{array}{l}\text { DOE - Office of Electricity Delivery and Energy } \\
\text { Reliability (OE) }\end{array}$ \\
\hline Rahim Amerkhail & Federal Energy Regulatory Commission (FERC) \\
\hline Michael Manwaring, Douglas Divine & National Hydropower Association (NHA) \\
\hline Mark Jones, Elliot Mainzer & Bonneville Power Administration (BPA) \\
\hline Xiaobo Wang & California Independent System Operator (CAISO) \\
\hline Zheng Zhou & Midwest Independent System Operator (MISO) \\
\hline Matt Hunsaker & Western Electricity Coordinating Council (WECC) \\
\hline Tuan Bui & California Department of Water Resources (CDWR) \\
\hline David Harpman & Bureau of Reclamation (Reclamation) \\
\hline Kyle L. Jones & U.S. Army Corps of Engineers (USACE) \\
\hline Scott Flake, Greg Brownell & Sacramento Municipal Utility District (SMUD) \\
\hline Paul Jacobson, Stan Rosinski & Electric Power Research Institute (EPRI) \\
\hline Alan Soneda & Pacific Gas and Electric Co. (PG\&E) \\
\hline Osamu Nagura & Hitachi Mitsubishi Hydro \\
\hline Teruyuki Ishizuki & Toshiba Corp. \\
\hline Rick Miller. Rick Jones & HDR Engineering Inc. (HDR |DTA) \\
\hline Jiri Koutnik, Maximilian Manderla & Voith Hydro \\
\hline Christophe Nicolet & Power Vision Engineering (PVE) \\
\hline Peter McLaren & Center for Advanced Power System (CAPS) \\
\hline Landis Kannberg & Pacific Northwest National Laboratory (PNNL) \\
\hline Klaus Engels & E.ON Wasserkraft GmbH \\
\hline Kim Johnson & Riverbank Power \\
\hline Steve Aubert, Le Tang & ABB Switzerland Ltd \\
\hline Ali Nourai & DNV KEMA \\
\hline
\end{tabular}


This page intentionally left blank. 


\section{Contents}

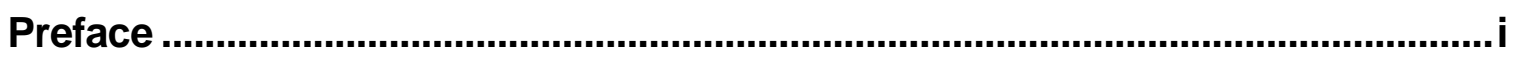

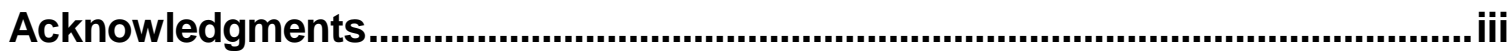

Section 1 Introduction ................................................................................ 1-1

Section 2 Ternary Pumped Storage Units ....................................................... 2-1

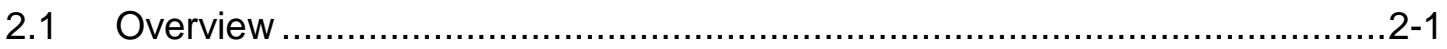

2.2 Advanced Pumped Storage Technologies..............................................2-2

2.3 Overview of Ternary Pumped Storage Units............................................2-2

Section 3 Modeling Ternary Pumped Storage Units ...................................... 3-1

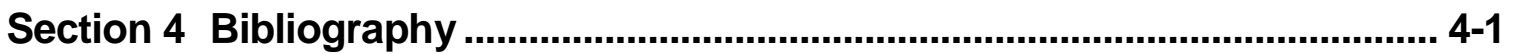


This page intentionally left blank. 


\section{Section}

\section{Introduction}

This report is one of a series of documents to be issued in the course of a U.S. Department of Energy (DOE) project titled "Modeling and Analysis of Value of Advanced Pumped Storage Hydropower in the United States." The objective of this overall effort is to investigate the advantages of recent advances in the design of pumped storage hydro plants. The objective of the first task of this project, "Develop Prototype Models of Advanced Pumped Storage Hydro (PSH) and Conventional Hydro $(\mathrm{CH})$ Plants," is to develop vendor-neutral dynamic simulation models for both fixed speed and adjustable speed PSH plants.

These models are a critical component of the analysis needed to plan, design, and operate the power system. Power system studies that use such models are done to:

- Determine operating strategies and power transfer limits,

- Study the impact of new generator additions,

- Determine the need for new transmission lines and substations,

- Investigate the stability of the system following large disturbances (transient stability) or incremental impacts (small signal stability), and

- Analyze the control of frequency and/or system voltages.

Note that these models are not the same as those used in the design of hydroelectric plants. Programs used for their design or hydraulic system analysis include much more detailed models of the hydraulic system and turbine physics.

The purpose of this report is to propose a power system dynamic simulation model structure for a ternary PSH unit employing a separate turbine and pump on a single shaft with the generator/motor. A companion report proposed a model structure for an adjustable speed PSH unit employing a doubly-fed induction machine (DFIM).

Section 2 of this report gives a summary of the technology and the basics of the operation of a ternary PSH unit, including both dynamic and steady state operation.

Section 3 provides a discussion on the modeling of these ternary pumped storage units. While the focus of this report is on how to model these units in the Power System Simulator for Engineering (PSS ${ }^{\circledR}$ E) program, the information is provided in a manner that 
is also applicable to modeling such devices in other commercial power system stability simulation programs.

Section 4 provides a bibliography. 


\section{Section}

2

\section{Ternary Pumped Storage Units}

\subsection{Overview}

The benefits of pumped storage units were recognized early in the development of electric power grids, especially as systems became larger and more interconnected. The first pumped storage plant in the United States began operation in 1929. While the design and engineering of more recent U.S. plants have improved efficiency and reduced environmental impacts, the basic design of modern U.S. pumped storage plants is similar to that used in those earlier plants.

Conventional pumped storage hydro (PSH) units have many similarities to conventional hydro plants. The major difference is, of course, that the flow is bidirectional for conventional PSH units. Usually, but not always, the same equipment is used for both generation and pumping; thus, the synchronous generator also operates as a motor, and the hydro turbine also operates as a pump. Both components are therefore reversible in their functionality. Some plants, particularly those with very high heads (head is the effective height between the water source and the turbine), may require separate turbines and pumps.

In practical applications, the transition from a generating to a pumping mode of operation (or vice-versa) is performed by the operator and takes several minutes (i.e., it is usually not a subject of power system dynamic simulation studies, except possibly for those used in the initial design of the plant). Thus, in most power system simulation studies, the generating and pumping modes of operation for conventional PSH units are studied separately. The system conditions being analyzed are appropriate for one mode or the other; for example, studies performed at peak load would model the units as generating, while light-load studies would model the units as pumping.

Because the focus of this project is hydroelectric power plants and pumped storage in particular, it is appropriate to give a general overview of the different types of hydroelectric units employed. There are two basic types of hydroelectric turbines: impulse turbines and reaction turbines.

Impulse turbines are generally used for installations where the head is high and the flow is relatively low (compared with that of the other turbine types described in the following text). The water is focused and directed though a nozzle, and the water stream impacts the turbine blades, thereby forcing the turbine to spin. Generally, the water leaves the nozzle at a high velocity and at atmospheric pressure, and two to six nozzles are distributed uniformly around the turbine circumference. The most commonly used impulse turbine design is the Pelton turbine. 
Reaction turbines are generally used for installations where the head is relatively low and the flow is relatively high. The transfer of energy from the water to the turbine does not occur at atmospheric pressure, as it does in the Pelton turbine. The water changes pressure as it moves through the turbine and gives up its energy. Thus, reaction turbines are either encased to contain the water pressure or submerged in the water flow. Energy from the pressure drop is transferred to the turbine through both the fixed guide vanes and the rotating runner blades. The most common reaction turbine types are the Kaplan and Francis turbines.

The Kaplan turbine is a propeller-like water turbine with adjustable blades. The combination of adjustable propeller blade angle and adjustable wicket gates enables high efficiency to be achieved over a wider range of head and flow.

The Francis turbine uses a spiral-shaped inlet and guide vanes to direct the water tangentially to the turbine runner. This radial water flow transfers the energy to the runner vanes. Adjustable guide vanes allow higher efficiency over a wider range of head and flow. Francis turbines are the basis for the reversible pump turbines used in pumped storage plants.

The technologies associated with the turbines just described are well known and documented in many references. These technologies are not new, as evidenced by their dates of invention (Francis in 1848, Pelton in the 1870s, and Kaplan in 1913). Of course, the actual design and physics of hydraulic turbines are much more complex than the few sentences above convey. Much effort has been put into research and design to improve the efficiency and reliability of these basic designs, as well as to reduce adverse environmental impacts, such as the impacts on erosion and fish populations.

\subsection{Advanced Pumped Storage Technologies}

The advanced pumped storage technologies can be grouped into two categories:

- Those that employ adjustable speed pump-turbines and

- Ternary units, which employ a separate turbine and pump on a single shaft with the generator/motor.

Various technologies can be employed in adjustable speed pump-turbines. The primary technology employed today for large pumped storage units is the combination of a DFIM and a Francis turbine. Models for this technology are described in a companion report Review of Existing Hydro Turbine-Governor Models.

The next section gives an overview of pumped storage employing ternary technology.

\subsection{Overview of Ternary Pumped Storage Units}

A ternary pumped storage system consists of a separate turbine and pump on a single shaft with an electric machine that can operate as either a generator or a motor. The turbine can be of either the Francis or Pelton design, depending on the hydraulic characteristics of the site. Pelton turbines are generally used for installations with very high head. 
The major difference between a ternary plant and other types of pumped storage plants is that the ternary plant can simultaneously operate both the pump and turbine. All other pumped storage plant designs operate either in a generating mode or a pumping mode, and the shaft rotates in opposite directions in these two modes.

The ability of the pump and turbine to operate simultaneously provides added flexibility in the plant's operation. The flexibility of the plant is also improved by having the pump and turbine on the same shaft and hence rotating in the same direction, thereby eliminating the need to reverse the rotation to transition from pumping to generating or vice-versa.

Because the pump and turbine are able to operate simultaneously, the hydraulic flow is more complex than it is in a conventional pumped storage unit. The ternary unit can operate with what is referred to as a "hydraulic short circuit." This is shown in Figure 2-1. The flow in the penstock is, of course, bi-directional; it goes from the head water to the tail water when the unit is generating electrical power, and from the tail water to the head water when the unit is absorbing electrical power (motoring).

The flow in the penstock is the net of the flow to the turbine and flow from the pump. The flow to the tailrace is this same net flow. One can think of a component of the flow circulating from the turbine to the pump (or vice-versa), which is the hydraulic short circuit referred to above.

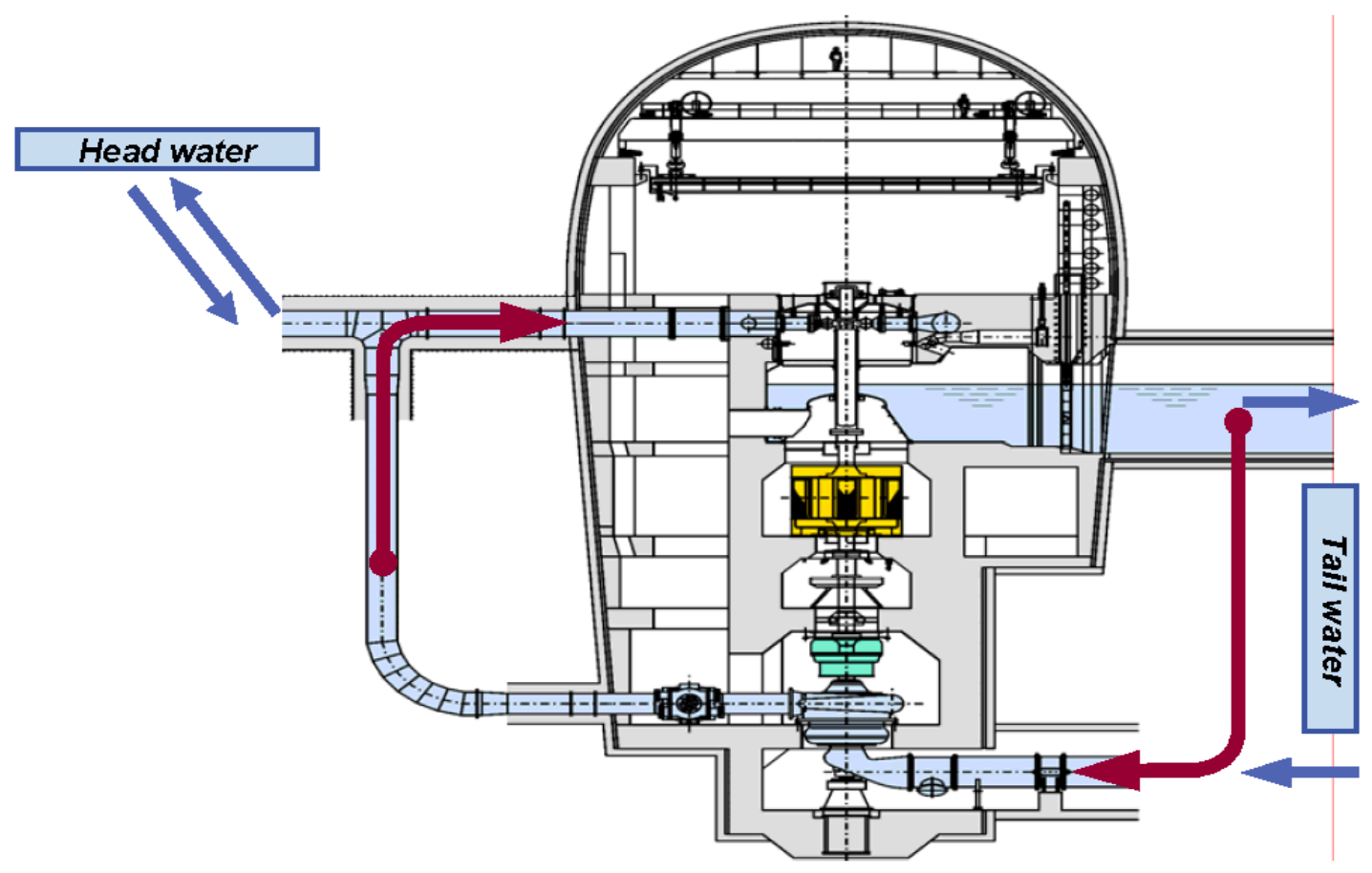

Source: Reference 7, Spitzer and Penninger (2008)

Figure 2-1 Ternary Units Demonstrating Hydraulic Short-Circuit Operation 
The three components - turbine, pump, and generator - can have two configurations. Figure 2-2 shows a configuration with a vertical shaft and the motor-generator located between the turbine and the pump. Figure 2-3 shows an alternative arrangement with the motor-generator located at the top, above both the turbine and the pump.

A horizontal configuration of the ternary units is also possible. A 240-MW HongrinLeman PSH plant in Switzerland is an example of a horizontal-shaft ternary plant.

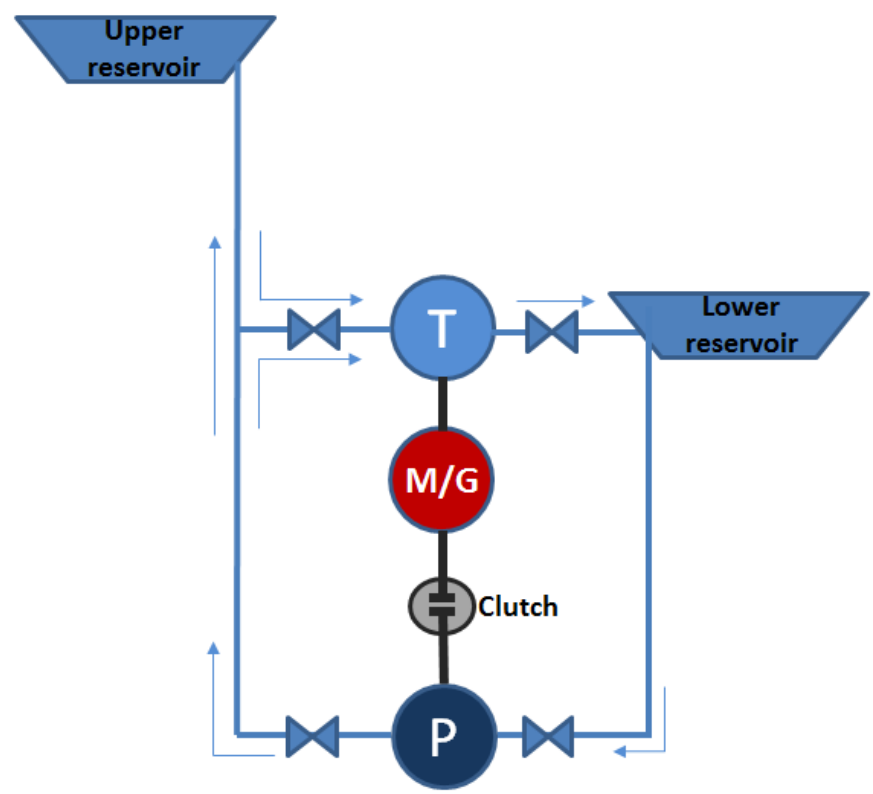

Figure 2-2 Ternary Unit with a Vertical Arrangement and Motor-Generator between the Turbine and Pump

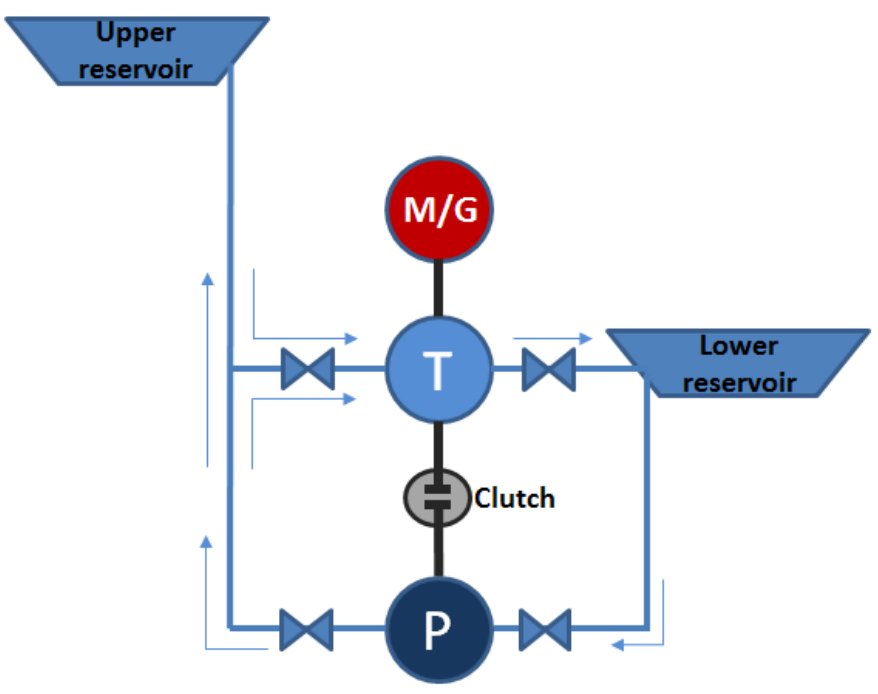

Figure 2-3 Ternary Unit with a Vertical Arrangement and Motor-Generator above the Turbine and Pump 
Typically, a clutch will be inserted on the shaft above the pump to disconnect the pump during turbine operation in order to avoid ventilation losses in the pump.

A system of guide vanes provides additional flexibility. If the plant is operating in generating mode, the guide vanes to the pump are closed, and the clutch is not engaged. The amount of generation is controlled by the position of the turbine guide vanes.

If the plant is operating in a pure pumping mode, the guide vanes to the turbine are closed, and the clutch is enabled. In this mode, the pump guide vanes are wide open, and there is no regulation capability.

If the plant is in the pumping mode and regulation is needed, both the pump and the turbine operate (i.e., employing the hydraulic short circuit). An example of this mode of operation is illustrated in Figure 2-4. The flow through the pump and the resulting torque applied to the shaft from the pump correspond to an electrical energy of $150 \mathrm{MW}$ drawn from the power system. However, the turbine guide vanes are adjusted so that the flow through the turbine and the resulting torque applied to the shaft from the turbine correspond to an electrical energy of $100 \mathrm{MW}$ supplied to the power system. The net result is that $50 \mathrm{MW}$ is drawn from the power system, and the flow pumped up to the reservoir is equivalent to $50 \mathrm{MW}$. Of course, there are some hydraulic losses in the loop owing to the circulating component of the flow, and careful hydraulic design is required. In this mode of operation, the guide vanes of the turbine are adjusted to provide the desired regulation.

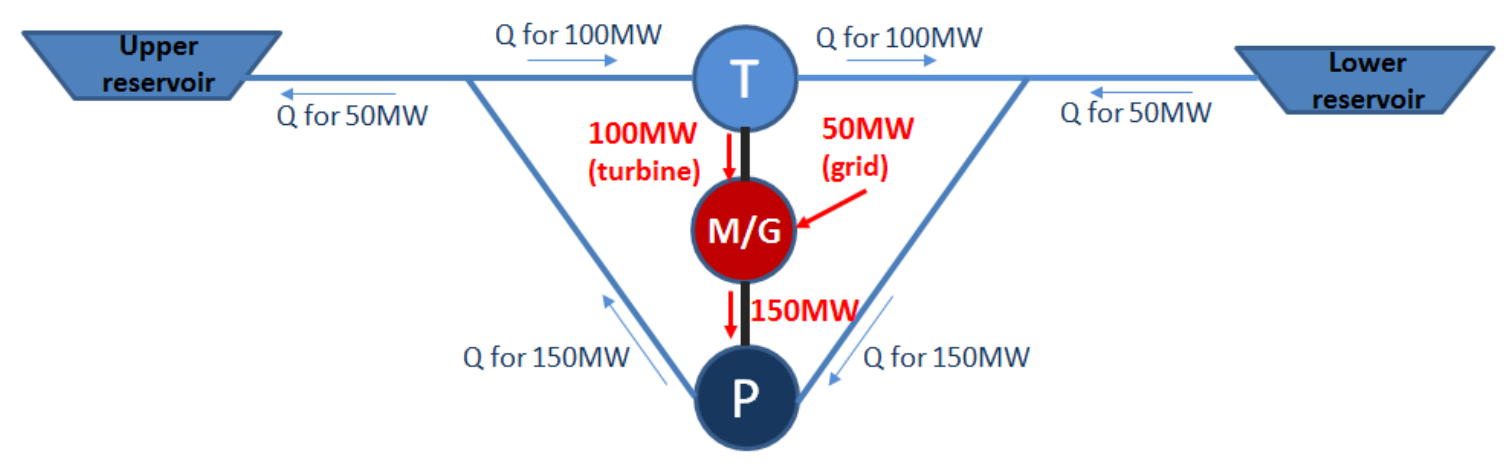

Figure 2-4 Example of Operation in Pumping Mode with Regulation Capability Using the Hydraulic Short-Circuit Concept

One major advantage of the ternary design is that the rotational direction of the motorgenerator is the same for both operational modes (i.e., there is no change in the direction of water flow to change from pumping to generating). The impacts from hydraulic transients are thus significantly reduced, and the machine can move rapidly from the full pumping mode to the full generating mode, unlike a reversible machine, which must stop before restarting in the opposite direction. 
Figure 2-5 gives typical startup and transition times and illustrates this advantage. The transition time from generating mode to pumping mode for a reversible pump-turbine is seen to range from 4 to 8 minutes, even for units employing advanced technologies. The transition time for the ternary units is much less, on the order of 0.5 to 0.75 minute.

The transition time for a reversible pump-turbine in the opposite direction, from pumping mode to generating mode, ranges from 1.5 to 5 minutes, while the transition time for the ternary units is again significantly less, on the order of 0.5 to 1 minute.

Depending on the system requirements, this decrease in transition time could be very advantageous. For example, consider a pumped storage unit operating in pumping mode at night, when a large amount of wind-powered generation is occurring. If there is a significant and fast drop in the wind energy, the ability of the pumped storage plant to transition quickly from pumping (and thus a system load) to generating could have a large impact on mitigating any resulting frequency deviations experienced by the system.

A second advantage of ternary units over reversible pump-turbines is improved efficiency. In a ternary unit, the pump and turbine are both optimized for efficiency. In a reversible unit, the design is necessarily a compromise to allow for operation as either a pump or a turbine.

Another advantage of a ternary unit is its ability to employ different turbine technologies for the pump and turbine; in particular, to employ a Pelton turbine for high-head installations.

Since the ternary unit does not employ power electronics, such as those used in DFIMbased designs, it does not have an impact on power quality, which can be a concern with regard to any design that employs power electronics.

A ternary unit also has a better natural response to system disturbances for which transient stability is a concern. A ternary unit inherently has a higher total inertia, since this inertia includes both a pump and a turbine in addition to the generator. This extra inertia also has a positive impact on the initial rate of frequency change for a system event, resulting in an imbalance of generation and load.

On the other hand, there are also some disadvantages of the ternary design. In general, it will have a higher first cost because the hydraulic design is more complex and because more equipment is required. The hydro plant will also be larger because of the additional equipment, and that additional equipment will probably result in increased operating and maintenance costs. 


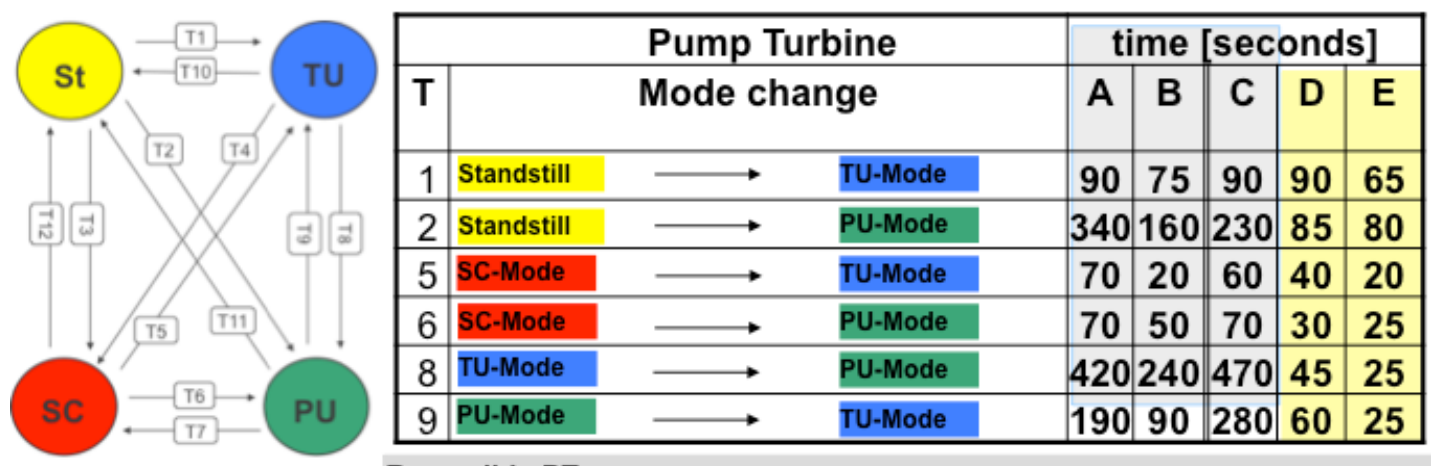

Reversible PT

A - advanced conventional (2012)

B - extra fast response conventional

C - VarSpeed, DFIM

Ternary set

D - with hydraulic torque converter + hydr. short circuit, horiz, with Francis Turbine E - same as E but vertical with Pelton Turbine

$\mathrm{TU}=$ Turbine $, \mathrm{PU}=\mathrm{Pump}, \mathrm{SC}=$ Synchronous Condenser

Source: Reference 6, Fisher et al. (2012)

Figure 2-5 Mode Change Times for Various Advanced Pumped Storage Technologies 
This page intentionally left blank. 


\section{Section \\ 3}

\section{Modeling Ternary Pumped Storage Units}

A ternary pumped storage hydro unit employs a separate turbine and pump on a single shaft with the generator/motor. The modeling of the generator/motor and its excitation system is exactly like the modeling of a conventional pumped storage hydro unit. Commercial power system simulation software packages, such as the PSS ${ }^{\circledR} E$ software and GE Energy's Positive Sequence Load Flow (PSLF) software, include models that represent the salient pole machine and many types of excitation systems. For more details on these models, please see the companion report, Review of Existing Hydroelectric Turbine-Governor Simulation Models.

The model for the prime mover and governor of a ternary pumped storage hydro unit must include models of the turbine and pump, which are on a single shaft with the generator/motor. The modeling of this equipment is the primary focus of this report.

In practical applications, the transition from a generating mode to a pumping mode of operation (or vice-versa) is performed by the operator. It usually is not a subject of dynamic simulation studies, except possibly for those used in the initial design of the plant. Thus, in most simulation studies, the modes of operation of a pumped storage unit are studied separately. The system conditions being analyzed are appropriate for one mode or the other; for example, studies performed at peak load would model the units in a generating mode.

The representation is a bit more complex for a ternary unit, since in one mode of operation, both the turbine and pump are active simultaneously. However, the models proposed are still based on the assumption that the mode of operation does not change (i.e., the unit either has the turbine in operation, has the pump in operation, or has both the pump and turbine in operation). The model does not include logic enabling a transition from, for example, operation with only the turbine in operation to operation with only the pump in operation.

While the following discussion is based on the PSS ${ }^{\circledR} E$ platform, the approach discussed below is applicable to any commercial simulation software package.

While the model for a conventional pumped storage plant requires separate models for turbine and pump operation, the model for the ternary unit incorporates all three modes (turbine operation only, pump operation only, or both turbine and pump operation) in a single model. 
In generating mode with only the turbine in operation, the model of the ternary unit is similar to that of a conventional hydro unit. Conventional models are used for the salient pole machine and the excitation system. The model of the turbine dynamics and the governor controls is shown in Figure 3-1. The machine will participate in the usual governor speed control, similar to the other generators on the system.

In pumping mode with only the pump in operation, the model of the ternary unit is again similar to that of a conventional hydro unit. Conventional models are used for the salient pole machine and the excitation system. The model of the pump dynamics and controls is shown in Figure 3-2. The machine will not participate in governor speed control.

The third mode of operation is pumping mode with the unit employing the hydraulic short circuit (ternary operation). For the hydraulic short-circuit mode, the model includes the following:

- Conventional models are used for the salient pole machine and the excitation system.

- The model of the turbine dynamics and the governor controls is as shown in Figure 3-1. The unit will adjust the gate position to participate in the usual governor speed control.

- The model of the pump dynamics and controls is as shown in Figure 3-2. The main inlet valve for the pump is adjusted to obtain maximum pump efficiency. The pump controls do not participate in the speed (frequency) control.

- The hydro and pump models include the logic to account for a design in which two ternary units (two sets of turbines and pumps) share the same penstock.

In ternary operation, the mechanical powers of the turbine and the pump provided by governor and pump models are summed to find the total mechanical power transferred to or from the common shaft. The rotor speed is determined by using the total inertia constant of the shaft including all three components (namely, the machine, the turbine, and the pump).

The operating mode (turbine operation only, pump operation only, or both turbine and pump operation) is selected via the proper setting of model constants.

As it is in the modeling of the conventional pumped storage units, the potential for ternary units to share a common penstock is included in the model. The model is structured to account for two ternary units sharing the same penstock, with each unit including a turbine, a pump, and a generator/motor.

The modeling of the penstock follows the approach given in Reference 5 (Hannet et al. 1999). The relationship between head and flow is given by the equation that follows. Note that each ternary set inherently has separate penstock sections supplying the turbine and the pump and hence uses two rows of the matrix. 


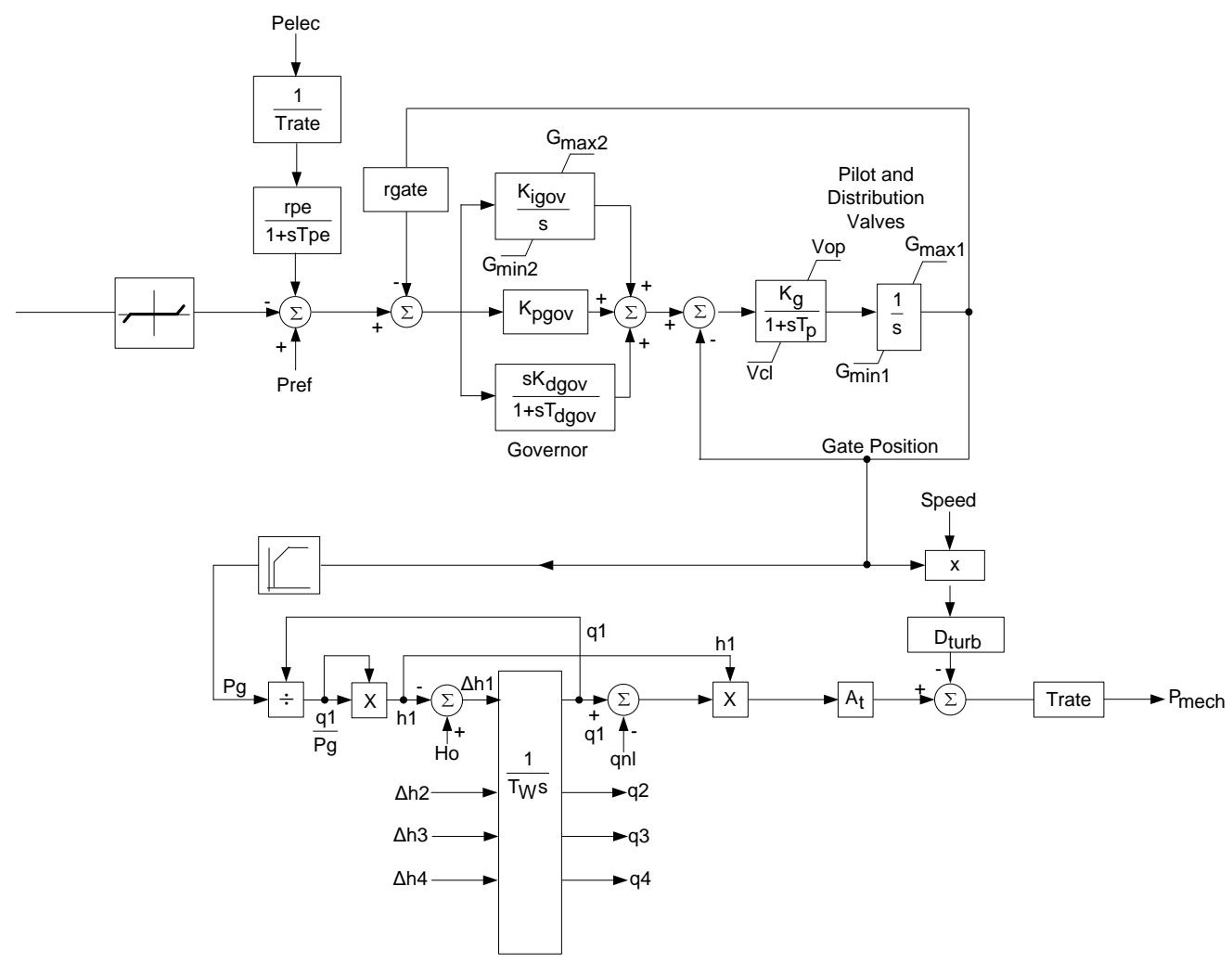

Figure 3-1 Model of the Turbine Dynamics and Governor Controls for the Ternary Unit

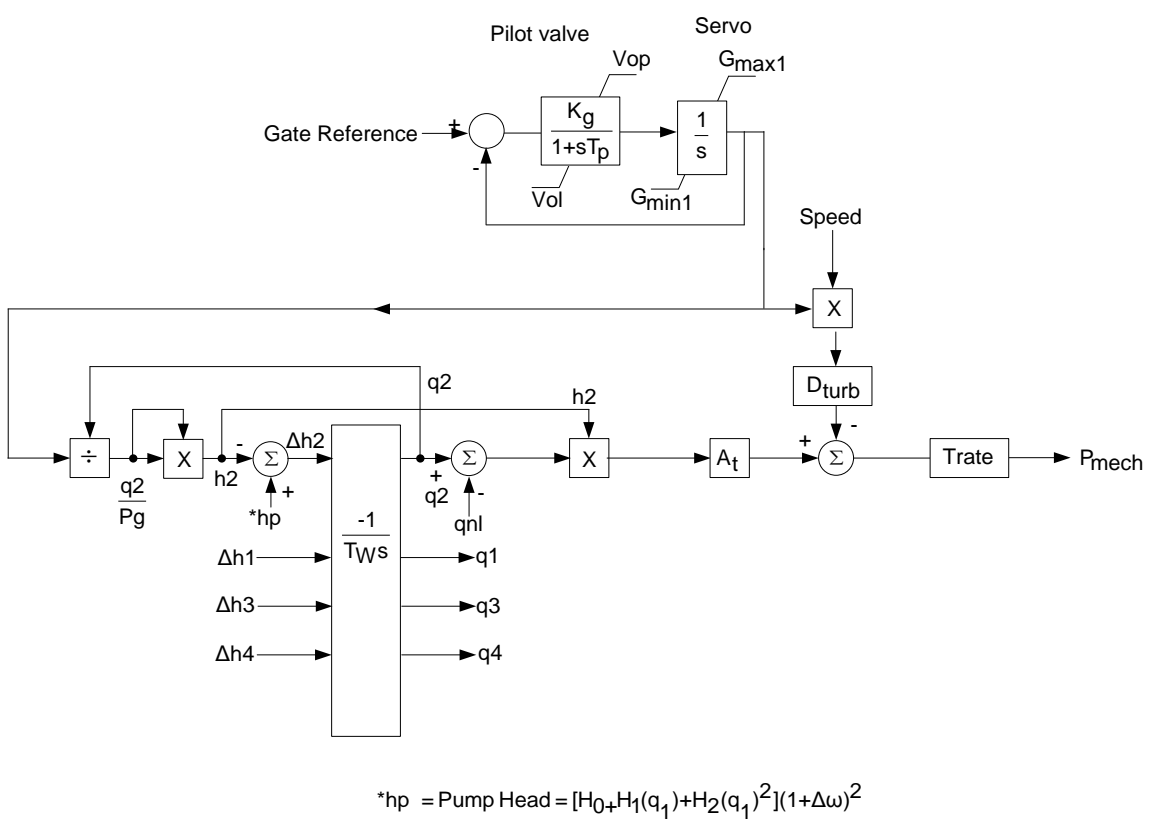

Figure 3-2 Model of the Pump Dynamics and Controls for the Ternary Unit 


$$
\left[\begin{array}{llll}
T w_{11} & T w_{12} & T w_{13} & T w_{14} \\
T w_{21} & T w_{22} & T w_{23} & T w_{24} \\
T w_{31} & T w_{32} & T w_{33} & T w_{34} \\
T w_{41} & T w_{42} & T w_{43} & T w_{44}
\end{array}\right] \cdot\left[\begin{array}{c}
\frac{d q_{1}}{d t} \\
\frac{d q_{2}}{d t} \\
\frac{d q_{3}}{d t} \\
\frac{d q_{4}}{d t}
\end{array}\right]=\left[\begin{array}{c}
\Delta h_{1} \\
\Delta h_{2} \\
\Delta h_{3} \\
\Delta h_{4}
\end{array}\right],
$$

where

$\mathrm{TW}_{\mathrm{ii}}=$ water starting time for the entire penstock length associated with Unit $\mathrm{i}$ at the rated flow for Unit I,

$\mathrm{TW}_{\mathrm{ij}}=$ water starting time for the penstock length common to Unit $\mathrm{i}$ and Unit $\mathrm{j}$ at the rated flow for Unit $\mathrm{j}$,

$\mathrm{TW}_{\mathrm{ji}}=$ water starting time for the penstock length common to Unit i and Unit $\mathrm{j}$ at the rated flow for Unit I,

$q_{i}=$ turbine flow in per unit for Unit $\mathrm{I}$, and

$\Delta h_{i}=$ turbine head difference in per unit for Unit i.

The turbine model includes a PID (proportional-integral-derivative) governor that can employ droop, based on either speed or gate position. The gate dynamics incorporate the ability to include a pilot valve time constant, gate opening and closing rate limits, and gate position upper and lower limits. If sufficient information is available, a look-up table can be used to account for nonlinearities in flow versus gate position.

In the pump model, a constant main inlet valve position reference is assumed. The pump head is used in place of the static head. The pump head is a function of the water flow, as shown in Figure 3-3 for a unit rotating at rated speed. This pump characteristic is characterized by a quadratic equation whose coefficients can be derived from pump characteristics provided in the specifications or determined by testing.

If speed deviations during transient conditions are noticeable, the flow, head, and power of the pump should be adjusted. The model allows adjustment per affinity laws proportionally to the speed (for flow), to the square of the speed (for head), and to the cube of the speed (for power).

The mechanical power is calculated as the product of flow and head. The efficiency should be accounted for in the gain $A_{t}$ (see Figures 3-1 and 3-2). Note that $A_{t}$ is proportional to the inverse of efficiency. 


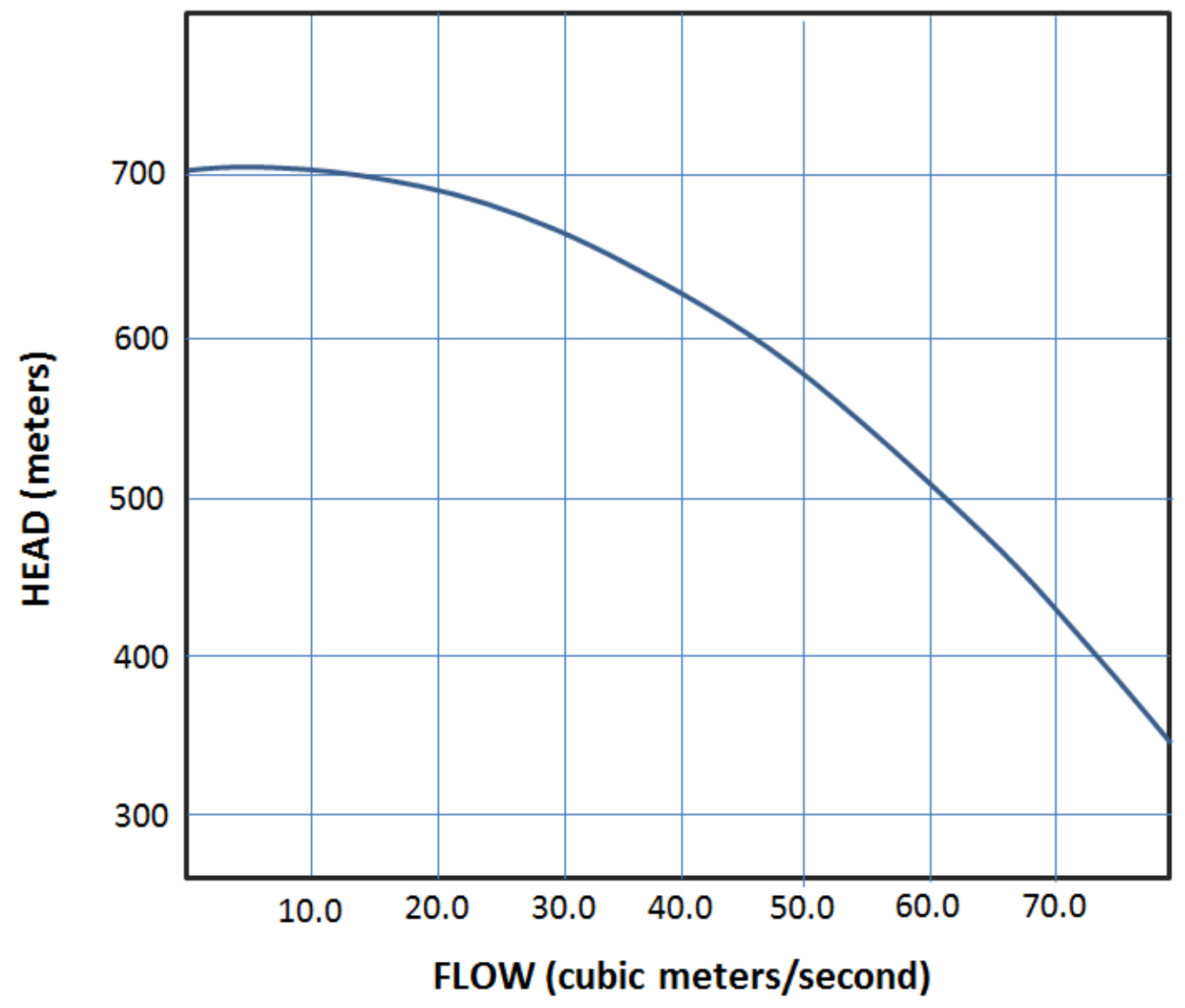

Figure 3-3 Pump Head versus Water Flow 
This page intentionally left blank. 


\section{Section}

4

\section{Bibliography}

1. Nicolet, C., Y. Vaillant, B. Kawkabani, P. Allenbach, J.-J. Simond, and F. Avellan, "Pumped Storage Units to Stabilize Mixed Islanded Power Network - A Transient Analysis," Hydro 2008 Conference, Ljubljana, Slovenia, October 6-8, 2008.

2. Taulan, J., P. Laurier, M. Bourrilhon, and L. Bornard, "Pump-Turbine Integration in Renewable Energy Systems," Paper No. 114, Waterpower XVI, Spokane, Washington, 2009.

3. "Hydropower Plant Kops II," Project brochure on the Kops II pumped storage plant, www.kopswerk2.at/downloads/Folder 061006 englisch, accessed in June 2012.

4. "Hydraulic Turbine and Turbine Control Models for System Dynamic Studies," IEEE Transactions on Power Systems, Volume 7, Issue 1, pp. 167-179, 1992.

5. Hannett, L.N., J.W. Feltes, B. Fardanesh, and W. Crean, "Modeling and Control Tuning of a Hydro Station With Units Sharing a Common Penstock Section," IEEE Transactions on Power Systems, Vol. 14, Issue 4, pp. 1407-1414, November 1999.

6. Fisher, R.K., J. Koutnik, L. Meier, V. Loose, K. Engels, and T. Beyer, "A Comparison of Advanced Pumped Storage Equipment Drivers in the US and Europe," HydroVision International, 2012.

7. Spitzer, F., and G. Penninger, "Pumped Storage Power Plants - Different Solutions for Improved Ancillary Services through Rapid Response to Power Needs," HydroVision 2008, July 2008.

8. Scherer, K., "Pumped Storage Energy," Hydro Generators, August 2008.

9. Avellan, F., "Storage Pumps \& Reversible Pump Turbines: Scientific and Technical Challenges," RGI Storage Workshop, Montreux, Switzerland, 2011. 
This page intentionally left blank. 
- 


\section{Argonne}

\section{Decision and Information Sciences}

Argonne National Laboratory

9700 South Cass Avenue, Bldg. 221

Argonne, IL 60439-4844

www.anl.gov 